\title{
Classical Case Report of Bogorad Syndrome
}

\author{
Tushar Kumar1 ${ }^{1}$ Vineet Gupta ${ }^{2}$, Prafulla Kumar Manjhi ${ }^{3}$, Kritika Gogia ${ }^{4}$, Rishabh Rathi ${ }^{5}$
}

${ }^{1}$ Department of Ophthalmology, Maharishi Markandeshwar Institute of Medical Sciences and Research, Mullana,

Haryana, India. ${ }^{2}$ Department of Ophthalmology, Maharishi Markandeshwar Institute of Medical Sciences and

Research, Mullana, Haryana, India. ${ }^{3}$ Department of Ophthalmology, Maharishi Markandeshwar Institute of Medical Sciences and Research, Mullana, Haryana, India. ${ }^{4}$ Department of Ophthalmology, Maharishi Markandeshwar Institute of Medical Sciences and Research, Mullana, Haryana, India. ${ }^{5}$ Department of Ophthalmology, Maharishi

Markandeshwar Institute of Medical Sciences and Research, Mullana, Haryana, India.

\section{INTRODUCTION}

The term "crocodile tears" is derived from the ancient belief that crocodiles weep after killing their victims. "Crocodile Tears Syndrome," also known as Bogorad syndrome, is the shedding of tears while eating or drinking in patients recovering from Bell's Palsy. It is a complication seen in 3.3\% of the patients suffering from Bell's palsy ${ }^{1}$. Bogorad syndrome (gustatory lacrimation) is an uncommon phenomenon seen after facial nerve palsy, characterized by incomplete recovery associated with uncontrollable watering from the ipsilateral eye while chewing. Fibers from the regenerating $7^{\text {th }}$ cranial nerve, destined originally for the submandibular ganglion, become misdirected to the pterygopalatine ganglion. Crocodile tear syndrome occurs approximately 6 to 9 months after an episode of Bell's palsy. Anatomically, the facial nerve (nervus intermedius) contains fibers for both the submandibular salivary gland and the lacrimal gland. After the facial nerve passes through the geniculate ganglion, the secretomotor fibers for the submandibular salivary gland travel with the main nerve trunk, whereas, the secretory fibers to the lacrimal gland disaffiliate from the facial nerve to join the greater petrosal nerve. These secretory fibers then relay in the sphenopalatine ganglion before innervating the lacrimal gland.

\section{PRESENTATION OF CASE}

A 34-year-old male with history of trauma to the right side of the temporal aspect of the head 1 year back developed hyper lacrimation of the right eye on chewing while recovering from Bell's Palsy since last 6 months. He was suffering from depression and was on antidepressants. Tear production was assessed using Schirmer's test.

\author{
Corresponding Author: \\ Dr. Vineet Gupta, \\ House No. 836, Sector 5, \\ Kurukshetra, Haryana, India. \\ E-mail: dr_vineet27@yahoo.co.in
}

DOI: $10.14260 / j e m d s / 2020 / 26$

Financial or Other Competing Interests: None.

How to Cite This Article:

Kumar T, Gupta V, Manjhi PK, et al. Classical case report of bogorad syndrome. J. Evolution Med. Dent. Sci. 2020;9(02):118119, DOI: $10.14260 /$ jemds/2020/26

Submission 14-12-2019,

Peer Review 25-12-2019,

Acceptance 01-01-2020,

Published 13-01-2020. 
On examination, general examination- normal, vitals \& BPnormal, systemic examination- normal except for mild facial palsy on right side associated with lagophthalmos and facial deviation, slit lamp examination of anterior chamber was found to be normal and other causes of epiphora were ruled out. Schirmer test 1 of the right eye was normal $(10 \mathrm{~mm}$ wetting). Schirmer test 1 after chewing gum was found to be increased (15 mm wetting).
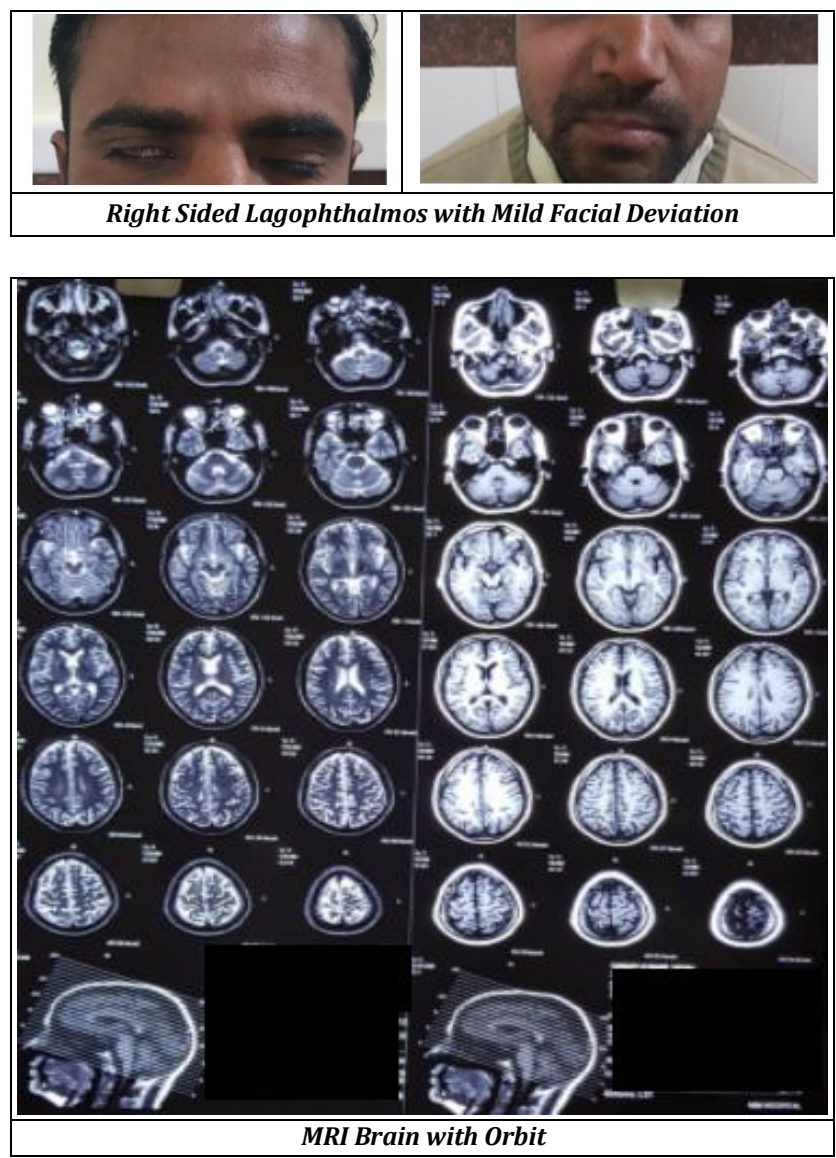

MRI of the brain (T1, T2, GRE axial \& coronal, DWI axial, BFFE axial sequences) showed small scattered micro bleeds bilaterally in the fronto-parietal region at the grey matter junction? Sequel of old diffuse axonal injury. He was advised intraglandular botulinum injection to the right lacrimal gland but refused and chose to be on regular follow ups.

\section{DISCUSSION}

In the recovery period following facial nerve injury, the regenerating salivary nerve fibers undergo synkinesis or are misdirected to ultimately innervate the lacrimal gland instead of the submandibular gland. Smell or taste of food excites the lacrimal gland to produce ipsilateral tearing. Another mechanism for crocodile tears syndrome is thought to be the formation of an artificial synapse at the injury site. This synapse allows the impulses to jump from one fiber to another and crossovers are likely, leading to crocodile tears syndrome.

A latency of 6 months is usually present between the onset of facial nerve palsy and crocodile tears syndrome for the nerves to regenerate ${ }^{2}$. Crocodile tears syndrome is a diagnosis of exclusion. Slit lamp examination of the eye and appendages is usually done to rule out other causes of epiphora. The basal tear secretion of an individual can be assessed by using the Schirmer's test. In the case of crocodile tears syndrome, it can be performed before and after gustatory stimulation to document increased tearing after salivation. It is also important to rule out other differentials like:

Orbicularis oculi weakness due to facial palsy: The orbicularis oculi muscle is tested by asking the patient to shut his or her eyes tightly while the examiner tries to open them. The force required to open the eyelid can be graded, and accordingly, the degree of muscle weakness can be ascertained.

Paralytic ectropion: The examiner performs the snap-back test to check for the lower lid laxity. A positive test is obtained when the eyelids spring back immediately into their original position after being pulled down by the examiner.

Nasolacrimal duct obstruction: ROPLAS (regurgitation on pressure over lacrimal sac) test is used to ascertain nasolacrimal duct obstruction.

\section{DISCUSSION OF MANAGEMENT}

Treatment depends on the severity of the hyper lacrimation and patient's satisfaction. Mild cases are generally managed by counseling and regular monitoring. Botulinum toxin (Botulinum A toxin) injection into the lacrimal gland is also thought to be a beneficial modality of treatment. ${ }^{3}$ Dose injected is 2.5 units transcutaneously or transconjunctivally. ${ }^{4}$ Its effect lasts for around 6 months. ${ }^{3}$ Transconjunctival route of injection is associated with fewer complications. Less drastic surgical options are used, and they are proving to be an effective way to control the tearing. Subtotal resection of the palpebral lobe of the lacrimal gland is considered beneficial by McCoy et al., and pre-operative Schirmer's test helps to control the amount of gland to be resected, thus preventing dry eye. ${ }^{5}$

\section{REFERENCES}

[1] Valença MM, Valença LP, Lima MC. Idiopathic facial paralysis (Bell' s palsy): a study of 180 patients. Arquivos de Neuro-Psiquiatria 2001;59(3-B):733-9.

[2] Modi P, Arsiwalla T. Crocodile Tears Syndrome. In Stat Pearls. Stat Pearls Publishing Sep 19, 2018.

[3] Nava-Castañeda A, Tovilla-Canales JL, Boullosa V, et al. Duration of botulinum toxin effect in the treatment of crocodile tears. Ophthalmic Plastic \& Reconstructive Surgery 2006;22(6):453-6.

[4] Montoya FJ, Riddell CE, Caesar R, et al. Treatment of gustatory hyperlacrimation (crocodile tears) with injection of botulinum toxin into the lacrimal gland. Eye (Lond) 2002;16(6):705-9.

[5] McCoy FJ, Goodman RC. The crocodile tear syndrome. Plastic and Reconstructive Surgery 1979;63(1):58-62. 